\title{
Considering Equity in Applying Western Standard Music Notation from a Social Justice Standpoint: Against the Notation Argument
}

\author{
Sanna Kivijärvi and Lauri Väkevä \\ Sibelius Academy, University of the Arts Helsinki, Finland
}

In this article, we consider Western Standard Music Notation (WSMN) as a normative communication system that, through representing certain cultural frameworks, may pose obstacles to musical learning, particularly in general music education. To focus this examination, we discuss different critical aspects of what we call the "notation argument": Because the skills of decoding WSMN are useful in learning certain kinds of music, they are useful in learning any musical tradition. Against this, we claim that, like any symbolic system, WSMN can have a variety of functions, not all of which may be pedagogically meaningful in given teaching-learning situations. WSMN may especially limit the musical learning of students who have difficulties in musical perception when working with written graphic symbolic representations. Emphasizing the development of literary notation skills in music education may thus hinder the progress of some learners, excluding them from curricular contexts where developing musical skills should arguably be deemed a right for everyone. We suggest shifting the theoretical focus from the pedagogical justification of applying WSMN and other notation systems to how social justice can be realized in music education through teaching accommodation guided by context-sensitive pedagogical tact.

Keywords: educational equity, music education, pedagogical tact, social justice, Western standard music notation

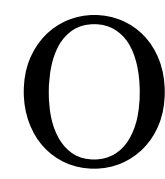

n the surface, Western Standard Music Notation (WSMN) has a neutral documentation function: marking key musical events, it enables musical works to be decoded by performers and analysts across cultural borders.

In this sense, WSMN can be seen as a universal system of representation that serves as a means to turn music into a transferable, visually analyzable cultural product. However, this system can also be seen as a cultural filter that "emphasise[s] attention to some aspects of sound while suppressing others" (Bennett 1983,217 ), directing the musicians' or analysts' focus on what is to be judged most

(C) Sanna Kivijärvi and Lauri Väkevä. The content of this article is the sole responsibility of the authors. The ACT Journal and the Mayday Group are not liable for any legal actions that may arise involving the article's content, including, but not limited to, copyright infringement. 
important in a particular cultural framework. In this outlook, WSMN shapes what it attempts to represent, implying certain ideological underpinnings that invite cultural criticism. Considered from the latter standpoint, the aim of teaching music through WSMN is to help students to become culturally legitimate practitioners who can discern musically meaningful sound events from those that are less meaningful against a certain value hierarchy. Here, one's ability to learn, make, and perform music is tied into how well one is able to decode music notation within a particular cultural framework, legitimated by a specific pedagogical tradition (Bennett 1983).

Underneath this rationale, one can identify what we would like to call the notation argument: because skills of decoding WSMN are useful in learning certain kinds of music in a certain context (historically, a Western music and Western music pedagogy context), they are useful in learning any kind of music (or at least most musics), and thus should be taught to all. While this use of the term "notation argument" is our own coinage and it has not been applied in the literature previously (cf. Fautley 2017), we believe that this way of thinking often frames curricular and pedagogical decisions over the role of WSMN in music education. Captivated by this logic, music educators may emphasize WSMN in the classroom without critical reflection on its relevance in different cultural learning contexts (Hess 2017). ${ }^{1}$ We want to problematize the notation argument by identifying different functions that such symbol systems as WSMN may fulfil in different cultural contexts, and, further, by paying attention to the educational justification for teaching notational literacy in different teaching-learning situations.

Recognition of the limits of WSMN is by no means new. Ethnomusicologists have argued for years that hopes for its universal applicability in representing musical events are at best pragmatic and at worst colonialistic (e.g., Seeger 1958, Merriam 1964, Nettl 1983). While culturally relativistic counter-arguments have been presented to criticize the wide applicability of this system in music education for years (see for instance Schippers 1996; Westerlund 1999; Dunbar-Hall and Wemyss 2000; Kwami 2001, 144; Green 2002, 28-9; Regelski 2007; Hess 2013; Bradley 2015; Roberts and Campbell 2015), and alternative notation systems have been located across music cultures (see e.g., Baily 1988; Garfias 1993; Gaare 1997; Hwang, Kim, and Yi 2010), to date, the debate of the educational applicability of WSMN has not focused on criticizing the notation argument from the standpoint

Kivijärvi, Sanna, and Lauri Väkevä. 2020. Considering equity in applying Western standard music notation from a social justice standpoint: Against the notation argument. Action, Criticism, and Theory for Music Education 19 (1): 153-73. https://doi.org/10.22176/act19.1.153 
of educational equity, understood as the quality of being just and fair in education. In this article, we argue that exclusive use of WSMN in music education may unfairly and unjustly limit the musical learning of those students who have difficulties in musical perception when working with written graphic symbolic representations, thus placing them in an unequal position in comparison to their peers who learn to decode such representations with less effort.

The request to offer equal opportunities for all students to learn music leads us to ask this question: If the application of WSMN creates inequity within music education, how can this be alleviated? This article provides theoretical points of departure for elaborating on this question. We first discuss how educational equity can be conceived as a basis of social justice in music education. We then examine the sociological conditions of music educators' professional competence, proceeding to a discourse on how the notation argument can be criticized by anchoring the conditions of music education to context-specific and situational pedagogical tact. In such education, the principle of accommodation should be used to determine when teaching for notational literacy is relevant. After that, we examine previous music education literature for cues about how music teachers' pedagogical tact can be exercised in culturally sensitive ways that support social justice as a basis for educational equity. We conclude by discussing the value of notation schemes in music education accommodation and suggest a critical reconstruction of the notation argument to better meet the needs of socially just and fair music education practice. Overall, we aim to provide a social justice perspective for reconsideration of the centrality of WSMN in music education.

\section{Educational equity as a basis for social justice in music education}

Social justice has been approached from various standpoints in music education, including economic, gender, and ableism perspectives (Benedict, Schmidt, Spruce, and Woodford 2015), and through theorizing the aspects that link it to music educational practice in different ways (Allsup 2007, Bowman 2007). A topical issue in this discourse is the relationship between equality and equity. The general idea in making the distinction is that the individual circumstances associated with social justice can be better addressed by thinking about them through the notion(s) of equity, rather than mere equality, as the latter is connected merely with the idea of

Kivijärvi, Sanna, and Lauri Väkevä. 2020. Considering equity in applying Western standard music notation from a social justice standpoint: Against the notation argument. Action, Criticism, and Theory for Music Education 19 (1): 153-73. https://doi.org/10.22176/act19.1.153 
providing equal opportunities or being satisfied with sameness in treatment (Benedict, Schmidt, Spruce, and Woodford 2015). The perspective of equity covers more ground, as it does not restrict its application to providing equal opportunities as a basis for fairness, but also takes heed of the underlying structural conditions that limit socially just opportunities. For instance, Allsup and Shieh (2012) argue that music education for social justice should start from recognizing and naming the individual circumstances and states of affairs through which and where inequities exist. They argue that music educators as "cultural workers" should seek for social justice by adapting more supportive policies that recognize the diversity of needs of the learners.

A commitment to equity guides one to pay attention to the educational justification of pedagogical practices, considering the cultural situatedness of this justification as a condition of realization of educational equity. From the equity standpoint, social justice in education is not fulfilled merely by attempts to provide equal opportunities for learning. It also requires a need to recognize inequality as a structural challenge, tied in countless ways to the social fabric of community life in cultural frameworks. Recognition of inequality also affords the recognition of the distribution of power, in the sense of grasping who has the prerogative to define what is meaningful in a given cultural framework. Education provides an important discursive context for addressing such questions because it is through educational institutions that such power is largely distributed within societies; this also applies to music education.

In music education, the shift of perspective from equality to equity means that teachers who want to provide conditions for just and fair teaching practice must bring more to the table than levelled classrooms equipped with accessible tools that can be used to achieve agreed-upon aesthetic goals following well-tried pedagogical methods. It requires ethical reflection on how and for what our educational practices structure learning situations, and it requires courage to criticize even the most widely accepted pedagogical decisions on the basis of this reflection. The decision on when such criticism is in order must be based on the awareness of the fragility of educational equity, where the latter is constantly challenged by preferences of cultural meaningfulness that are taken for granted, and that, on closer inspection, often turn out to be ideologically founded. The use of WSMN in teaching music may be subject to as much criticism as any culture-specific practice;

Kivijärvi, Sanna, and Lauri Väkevä. 2020. Considering equity in applying Western standard music notation from a social justice standpoint: Against the notation argument. Action, Criticism, and Theory for Music Education 19 (1): 153-73. https://doi.org/10.22176/act19.1.153 
ultimately, it should be the pedagogical situation that offers the testing ground of its viability and pedagogical potential.

\section{Music educator's professional competence, teacher autonomy, and the notation argument}

The music educator's professional competence has often been linked with musical identity, relating to the alternation between the roles of musician and educator based on a variety of musical preferences (Hargreaves, Purves, Welch, and Marshall 2007). In line with this, Bouij (2004) argues that music-specific identities are generally emphasized over student-centered teacher identities in music education. In turn, Ballantyne (2005) suggests that how a music teacher perceives her own musical abilities is likely to influence her professional identity; the more musical self-efficacy a music teacher has, the more likely she is to define herself as a musician. However, if a music teacher perceives her musical abilities as lacking, she is more likely to perceive her identity as that of a teacher (Ballantyne 2005).

Such anchoring of the music educator's professional competence to the eitheror decision regarding whether she should emphasize musical or educational preparedness has also been criticized. For instance, according to Bowman (2007), a music education professional is not simply a musician who happens to teach music or has some training in music education; rather, a professionally adept music educator is someone who fluently combines musical and educational capabilities (see also Elliott 1995, 2009; Elliott and Silverman 2015). Such views connect the competence of music educator or "music educatorship" more tightly with pedagogical competence, making no value distinction between musical and pedagogical skills, but instead seeing both as sides of the same coin, necessary for any music educator to practice her profession capably in pedagogical situations.

The association between the music educatorship and mastering of specific musical traditions links to the problem of how and when to use WSMN in music education, raising the more extensive question of whether teaching notation-based literacy as the basis for musical learning should be judged to be a necessary part of a music educator's professional toolset. From the standpoint of the notation argument, the affirmative answer seems to be natural; to the degree that any approach helps the student to learn music, it should be part of the teacher's methodological

Kivijärvi, Sanna, and Lauri Väkevä. 2020. Considering equity in applying Western standard music notation from a social justice standpoint: Against the notation argument. Action, Criticism, and Theory for Music Education 19 (1): 153-73. https://doi.org/10.22176/act19.1.153 
toolbox. In addition, research indicates that learning musical literacy may have transfer effects to other areas of learning, such as language reading skills (Darrow 2008; Corrigal and Trainor 2011; Flaugnacco et al. 2015), which might offer additional justification for studying standardized notation systems. An alternative perspective could be to connect the relevance of the use of music notation to teacher autonomy, understood here as a teacher's potential to make her own decisions about the approaches, materials, and assessment used in specific educational contexts. While many scholars have argued that music educatorship should be built on strong musical proficiency that consists, partly, of what Elliott $(2009,128)$ calls "formal musicianship" and Elliott and Silverman $(2015,217)$ call "verbal musical thinking and knowing," one may also approach the matter from the standpoint of pedagogical competence. In this outlook, teaching accommodation suggests itself as a key dimension of realizing the music educator's autonomy.

From the standpoint of teaching accommodation, a professionally adept music teacher never operates on the basis of tradition alone, for her pedagogical choices are influenced by particular teaching-learning situations and are embedded in cultural contexts for the realization of social justice. Here, the possibility of realization of social justice is based on the idea that through accommodation, the special needs of individual learners can be acknowledged. While understanding the cultural frameworks that help the students to grasp the meaningfulness of what they learn is important, teaching accommodation should also build on recognition of the pedagogical moment-a moment that demands "acting pedagogically responsibly and appropriately in everyday situations" (van Manen 2015, 18)-that should guide all pedagogical decisions, including the decision whether to use WSMN. In a pedagogical moment, pedagogical intent rather than the tradition of the subject matter becomes the focus of the teacher's praxis, informing the types of intentional actions or interactions that cultivate and support students' learning, development, and well-being in a constructive manner (van Manen 1991). In the context of music education, pedagogical intent may include decisions about whether to use notation systems, but, depending on the specific pedagogical moment, it may also include decisions that judge their application irrelevant or even harmful. In pedagogical decision making, then, an educator should be guided by the theoretical and practical principles of her discipline in terms of staying sensitive to the cultural context that provides the basis for understanding the significance of what is taught, but,

Kivijärvi, Sanna, and Lauri Väkevä. 2020. Considering equity in applying Western standard music notation from a social justice standpoint: Against the notation argument. Action, Criticism, and Theory for Music Education 19 (1): 153-73. https://doi.org/10.22176/act19.1.153 
most of all, remain open to the students' situational needs. Teaching accommodation requires that a teacher is able to view educational situations from each student's perspective to make appropriate pedagogical decisions on the spot. In other words, it is the teacher's pedagogical tact, rather than the presumed value of the traditional tools of learning of certain musical traditions that should drive decision making in such situations (van Manen 1991, 2015).

What does this have to do with equity and social justice? We would like to argue that by staying aware of the implications of the teaching-learning situations as well as the cultural contexts of teaching, a music educator can better make decisions over what to teach and how. While the cultural context sets certain expectations for pedagogy, the final decision about what needs to be done is the teacher's, and the best way to guarantee educational equity-in the sense of providing education just and fair-is to exercise pedagogical tact. Adherence to musical identity determined by a strong orientation of working within the bounds of certain music traditions can limit a music educator who strives to accommodate her teaching for the benefit of each student, guided by her professional commitment and autonomy to make just and fair decisions in the classroom. The notation argument, even if seemingly making sense within the bounds of certain cultural frameworks, may turn out to be too limiting when the teaching-learning situations require accommodated solutions.

\section{Criticizing the notation argument based on music education research}

Research on the use of WSMN in music education has largely focused on the student's development and the improvement of individual music literacy skills, not infrequently in connection with learning music in the context of the pedagogicalcultural framework of Western art music education. In this context, research on equity issues has mainly considered how WSMN could be taught to all students regardless of their background (e.g., Junda 1994; Hultberg 2002; Kopiez and Lee 2006, 2008; Darrow 2008; Tan, Wakefield and Jeffries 2008; Gudmundsdottir 2010; Hasu 2017; see also Lane 2006; Bautista, Pérez-Echeverría, Pozo and Brizuela 2009; Marin, Pérez-Echeverría and Hallam 2012; López-Íñiguez and Pozo 2014). Some scholars have criticized the requirement for learning and teaching WSMN by linking the issue to other areas of inequity in music education, such as

Kivijärvi, Sanna, and Lauri Väkevä. 2020. Considering equity in applying Western standard music notation from a social justice standpoint: Against the notation argument. Action, Criticism, and Theory for Music Education 19 (1): 153-73. https://doi.org/10.22176/act19.1.153 
the role of non-classical genres in music curriculum or "methodolatry" (Regelski 2002, see also Bennett 1983, Björnberg 1993) which, according to Regelski (1998, 10), refers to "attachment to particular 'techniques,' 'methods,' or 'materials' of teaching that too often fall far short of the kind of effective pragmatic results that are the ethical basis of teaching as a professional praxis."

Part of the problem of assuming extensive applicability for WSMN in music education may lie in how music itself is conceived. A common way to understand music in an educational context is to grant it symbolic value. For example, Swanwick $(2001,232)$ conceptualizes music as "an activity that is in some way representative of our experience of the world." From this perspective, music can be conceived primarily as a symbolic system-a presumption that obviously leans on the idea that music can be representative of something outside itself. Following this logic, graphic notation offers a secondary symbolic system that can help one to grasp the primary symbolic system, involving "a translation from one representational domain to another" (232). In this translation, "some loss of information is inevitable," for any secondary symbolic system is selective of the primary significance of the primary symbolic system (232). Thus, WSMN, like all secondary symbolic systems, restricts the scope of the meaningfulness of what it symbolizes, making its object more easily transferable and applicable in a variety of pedagogical situations.

In line with this, it is easy to see that WSMN highlights the most essential musical parameters for the aesthetic sensibilities developed in the Western art music tradition from which it originates. In terms of Meyer (1989), its graphic representation mode primarily emphasizes the "syntactic" parameters of pitch and duration. While WSMN also has sophisticated ways of representing what Meyer (1989) called non-syntactic or "statistical" parameters (e.g., dynamics), it is still most powerful in depicting melodic/harmonic and rhythmic/metric regularities. This has turned out to be an extremely efficient communicative mode in a musical tradition that largely relies on compositional architectonic forms based on regulation of pitch and rhythm. Yet, in genres in which musical structuring takes place in an alternative manner (e.g., where the performer is allowed great freedom to vary the musical form from performance to performance), notation systems that do not rely primarily on representing structurally complex forms of pitch-rhythmic configurations have turned out to be more useful. For example, commercially distributed 
popular music notation often presents only a simplified melody line, lyrics, and chord symbols and/or guitar or bass tablatures; the rest of the musical information is usually "copied" directly from recordings by ear or otherwise interpreted without written instructions (Lilliestam 1996). Percussion notation, tablature, and a variety of notation systems based on numbers, letters, colors, and shapes, are also common in musical traditions that have their origins outside Western art music practice (Gaare 1997). Some of these alternative systems were primarily developed to serve pedagogical needs rather than the needs of representation-for example, the color music notation system reported by Kuo and Chuang (2013) and the Figurenotes system reported by Kivijärvi (2019). Whether such pedagogically designed systems are ultimately meant as support devices for mastering WSMN depends on the designer's intent and the context of the application.

It may be argued that generalizing genre-specific focuses on notational literacy skills may be problematic, as notation systems used in learning music vary considerably from one music culture to another, and in many musical contexts a musical representation system may not be considered necessary at all (McCarthy 2009; Bennett 2015, 39). Yet, WSMN is by far the most commonly applied system of musical representation in music education worldwide, and its hegemony in this context seems to be generally supported by the notation argument as applied in music education (Spruce 2001; Nolet 2007; Tokita and Hughes 2008; Karlsen and Westerlund 2015; Fautley 2017; Hess 2013, 2017). This has not prevented several music education researchers and practitioners from challenging its hegemony, contending that the learning of many music genres is not dependent on musical literacy (e.g., Lilliestam 1996; Green 2002; Bradley 2015; Powell, Krikun, and Pignato 2015). Such critical views can be aligned with the claim that the educational use of WSMN, or any other musical notation system, should be determined by the dynamism of the students' experiences in their cultural context (Väkevä and Westerlund 2007). Thus, it seems that there is a need for a broader understanding of the pedagogical meaning of musical notation in music education, especially concerning how it extends normative cultural control to some learners while excluding others. To this, we would like to add the recognition of the need to accommodate teaching to the situational needs of the individual students; while it is important to work within a cultural framework that makes sense to the learners, it is equally important to pay attention to the idiosyncratic ways in which they make music part

Kivijärvi, Sanna, and Lauri Väkevä. 2020. Considering equity in applying Western standard music notation from a social justice standpoint: Against the notation argument. Action, Criticism, and Theory for Music Education 19 (1): 153-73. https://doi.org/10.22176/act19.1.153 
of their lives. Again, from the standpoint of social justice, this requires more than providing equal opportunities for becoming familiar with different musical traditions: the music educator should be able to accommodate her teaching to the demands of specific teaching-learning situations while keeping an eye on the cultural conditions of realization of educational equity.

Earlier scholarship in music education suggests that, rather than simply providing a universal standard for how music is to be represented graphically, WSMN can be interpreted as a culture-specific globalized secondary-level symbolic system that filters certain musical parameters for representation in order to guide performance of musical works or to make them easier to analyze in a given cultural framework. While there is a practical benefit to having such an ostensibly universalized representation system at hand, its dependence on a cultural framework that defines the aesthetic priorities of musical meaningfulness in certain way also implies dangers. This makes the notation argument subject to criticism, as it appears to be based on culture-specific judgments that are dependent on how far one can expand the value of pedagogical approaches developed in one musical tradition. While seemingly natural from the inside perspective of how a tradition has been historically transmitted, such judgments are open to cultural criticism that can take as its point of departure the situational needs of the learners in a variety of cultural contexts. This expands the claim for providing equal conditions for musical learning to acknowledge the conditions of educational equity, interpreted here as a function of social justice.

\section{Critical reconstruction of the notation argument}

Laes and Westerlund (2018) argue that music education scholarship seems to have largely presumed that students should fit into existing musico-pedagogical practices that normatively guide the curricular choices made by teachers. If such practices do not serve the situational learning needs of students, the music educator is expected to find ways to make them fit into them, rather than finding alternative approaches (Bell 2017). One example of such instructional determination is the methodological focus on acquiring notational literacy, based on a notion that every student needs to learn skills to decode WSMN or other standard notation system as part of her musical development. In this scheme, one strategy of tactful music

Kivijärvi, Sanna, and Lauri Väkevä. 2020. Considering equity in applying Western standard music notation from a social justice standpoint: Against the notation argument. Action, Criticism, and Theory for Music Education 19 (1): 153-73. https://doi.org/10.22176/act19.1.153 
pedagogy could be to find ways to develop music reading skills, where alternatives to WSMN could be used as preliminary steps in the learning process (e.g., the simplified pedagogical notational schemes discussed above). From the standpoint of equity in opening new creative possibilities in learning situations for all, music educators should be equipped with a range of pedagogical knowledge and capabilities, including the ability to use a variety of notational systems when feasible. However, some alternate schemes of notation may be also understood as methods that are or were originally targeted at restricted groups of students (e.g., Figurenotes). As such, they might not even be meant to lead into acquiring more complex notational literacy, as such literacy might be irrelevant to the students or outside their scope.

In general music education, it would be viable to presume that many (perhaps most) students have difficulties in learning WSMN, but this in no way undermines their ability to learn music. Hence, it would seem that the notation argument only applies to a minority of students studying in specialized contexts, and possibly not even all of them. On the basis of this presumption, we propose that (1) extensive use of WSMN especially in general music classes may pose an obstacle to equity in learning music and that (2) ways should be considered to replace the cultural hegemony of WSMN in musico-pedagogical practice that would be sensitive to the cultural context of teaching and to the teaching-learning situation at hand. While such alternative notation systems as Figurenotes seem to offer handy ways to grasp and perform musical events without the need to proceed to learning WSMN (but also providing avenues into it, when needed), we suggest that the application of such alternative systems should also be determined by pedagogical tact, a teacher's ability to relate the meaningfulness of what is to be learned and the method of learning to the situational needs of a student who constructs meanings within certain cultural framework. Instead of seeing alternative notation systems as universal pedagogical tools, then, we suggest seeing them as tools that are useful in certain purposes subject to the pedagogical moment.

On the basis of the above discussion, musico-pedagogical practices guided by the notation argument seem to work best in cases where the students are able to learn symbolic decoding skills. In contexts where the students are unable to decode sonic information on the basis of the written symbolic system (e.g., because of a cognitive or other disability or the cultural irrelevance of such systems), teaching

Kivijärvi, Sanna, and Lauri Väkevä. 2020. Considering equity in applying Western standard music notation from a social justice standpoint: Against the notation argument. Action, Criticism, and Theory for Music Education 19 (1): 153-73. https://doi.org/10.22176/act19.1.153 
WSMN can be regarded as non-pedagogical practice (or even malpractice) because of the lack of pedagogical tact that adjusts both to the individual teaching-learning situation and the cultural context of making music meaningful. Guided by the notation argument, an exclusive focus on learning notational musical literacy may hinder the progress of many learners by excluding them from the curricular context where developing musical skills is deemed a right for everyone (Mills and McPherson 2006; see also McPherson 2005).

Previous research has pointed towards a strong position of WSMN in music education. For example, according to Spruce (1999, 2001), the approaches of assessment in music education are based on beliefs about the supremacy of Western art music and music notation although the national core curricula emphasize diversity of musical contents, such as the inclusion of contemporary styles and nonWestern musics in classroom practices. Following a similar line of thought, Johnson (2004) states that the logic and notation associated with the Western classical tradition provide the basis for music education practice in the United States (see also Kwami 2001; Spruce, 1999, 2001; Hess 2013; Roberts and Campbell 2015; Yoo 2017). Kelly-McHale and Abril (2015) write that the four most common approaches in general music education in the United States are Orff, Kodály, Dalcroze, and Gordon, and that "each of these approaches is based upon the Western European music paradigm, using repertoire, notation, and a reverence for that art music tradition" (188). Tokita and Hughes (2008) describe how students and student teachers are extensively exposed to Western art music in educational institutions throughout Japan, leading to music (education) practices that are at least to some degree westernized and based on WSMN. They also explain how WSMN is unable to capture many important subtleties of Japanese music. ${ }^{2}$ Accordingly, Hess (2013) writes that "colonialism is embedded in dominant paradigms of music education; we see it through the dominance of Western classical forms and Western standard notation" (16; see also Westerlund 1999; Roberts and Campbell 2015). Regarding higher education in music, Karlsen and Westerlund (2015) state that "most music teachers were, and in many cases still are, educated within the realm of Western music and its notation-based teaching and learning practices" (402).3 Fautley (2017) summarizes that the role of notation in music education is a contested matter that is connected with issues of equity and justice in and through education, and, as such, it should be of growing concern for educational

Kivijärvi, Sanna, and Lauri Väkevä. 2020. Considering equity in applying Western standard music notation from a social justice standpoint: Against the notation argument. Action, Criticism, and Theory for Music Education 19 (1): 153-73. https://doi.org/10.22176/act19.1.153 
practitioners and leaders. We share this concern and suggest that a more general situational rationale should be applied in making pedagogical decisions such as using WSMN in a music classroom.

We conclude that it is worth investigating whether music education can create equal access to learning through alternative notation systems and whether there are cases in which no symbol systems are needed at all. A major motivation for the development of alternative notation systems seems to have been advancing of music making and learning among those who cannot or find no need to learn WSMN. Yet the relevance of such systems should be determined situationally and contextually, paying attention to the possibilities of realizing the curriculum for certain students within certain contexts. If music education aims at educational equity by opening new creative possibilities in learning situations for all, music educators should be prepared with a variety of pedagogical knowledge and skills. This should include capabilities to implement alternative notation systems in a variety of contexts and to work without such systems according to the situational needs.

So far, many alternative notation systems have been targeted to specific groups of students, e.g., students with special needs. In light of the argument developed in this article, notation systems in general should be understood as pedagogical tools that can be adapted tactfully, acknowledging the possibility that sometimes they might not be needed at all. In addition, alternative notation systems may be perceived to offer possibilities to transgress the traditional methodological use of WSMN in pedagogical practice, suggesting new ways to meet learners' diverse pedagogical needs and, thus, to tackle educational inequity.

While WSMN no doubt continues to serve as an efficient means of communication and coordination of musical performances in the context of the traditional pedagogy of Western art music and its derivatives, it should be recognized that musicians globally have other means of organizing their musical practices; the collective aspects of music making can be enacted with alternative notation systems or playing by ear, and the latter approach might also enable musical responsiveness more directly and intuitively than the use of notation affords (Bamberger 2005). All of this seems to suggest that musical notation schemes have more than one function, and it is the teacher's pedagogical tact that should guide her choices regarding how to apply such systems in teaching-learning situations and cultural contexts.

Kivijärvi, Sanna, and Lauri Väkevä. 2020. Considering equity in applying Western standard music notation from a social justice standpoint: Against the notation argument. Action, Criticism, and Theory for Music Education 19 (1): 153-73. https://doi.org/10.22176/act19.1.153 


\section{Acknowledgments}

This research has been undertaken as part of the ArtsEqual project funded by the Strategic Research Council of Academy of Finland (programme: Equality in Society, project number: 314223/2017). The research has also been funded by the Finnish Concordia and Cultural Foundations.

\section{About the Authors}

Sanna Kivijärvi is a doctoral candidate at Sibelius Academy, University of the Arts Helsinki. Her dissertation examines the approximation of micro- and macro-level education policies by analyzing an innovation for educational equity, Figurenotes (Kuvionuotit), from both pedagogical and educational policy perspectives. In addition to her doctoral research, Kivijärvi has published several peer-reviewed articles and book chapters on accessibility and equity issues in the Finnish music education system and beyond. Among other teaching assignments, she has worked as a lecturer in music education at Sibelius Academy. During the academic year 2019-2020, Kivijärvi is a Fulbright visiting scholar at Teachers College, Columbia University and at Steinhardt School of Education, Culture, and Human Development, New York University. Email: sanna.kivijarvi@uniarts.fi

Lauri Väkevä is a vice-rector of University of Arts Helsinki and professor in music education at Sibelius Academy of the University of the Arts Helsinki. A co-editor of three books, he has also published several book chapters and numerous articles in peer-reviewed journals, as well as presented papers in international conferences in the fields of music education, musicology, music history and popular music studies. Väkevä's main research interests cover Afro-American music, popular music pedagogy, history of popular music, pragmatist aesthetics, philosophy of music education, informal learning, digital music culture, educational systems and history of education. Aside of academic career, his work assignments have covered working as a musician, music journalist, general music teacher, and instrumental teacher. Email: lauri.vakeva@uniarts.fi

\section{References}

Allsup, Randall Everett. 2007. Extraordinary rendition: On politics, music, and circular meanings. Philosophy of Music Education Review 15 (2): 144-54.

Allsup, Randall Everett, and Eric Shieh. 2012. Social justice and music education: The call for a public pedagogy. Music Educators Journal 98 (4): 47-51.

Baily, John. 1988. Anthropological and psychological approaches to the study of music theory and musical cognition. Yearbook for Traditional Music 20: 11424.

Kivijärvi, Sanna, and Lauri Väkevä. 2020. Considering equity in applying Western standard music notation from a social justice standpoint: Against the notation argument. Action, Criticism, and Theory for Music Education 19 (1): 153-73. https://doi.org/10.22176/act19.1.153 
Ballantyne, Julie. 2005. Identities of music teachers: Implications for teacher education. In Teacher education: Local and global: Australian teacher education association conference proceedings, edited by Maxine Cooper, 39-44. Gold Coast, Australia: Australian Teacher Education Association.

Bamberger, Jeanne. 2005. How the conventions of music notation shape musical performance and perception. In Musical communication, edited by David Hargreaves, Dorothy Miell, and Raymond MacDonald, 143-70. Oxford: Oxford University Press.

Bautista, Alfred, Ma del Puy Pérez-Echeverría, Juan Ignacio Pozo, and Bárbara Brizuela. 2009. Piano students' conceptions of musical scores as external representations: A cross-sectional study. Journal of Research in Music Education 57 (3): 181-202. https://doi.org/10.1177/0022429409343072

Bell, Adam P. 2017. (dis)Ability and music education: Paralympian Patrick Anderson and the experience of disability in music. Action, Criticism, and Theory for Music Education 16 (3): 108-28.

Benedict, Cathy, Patrick Schmidt, Gary Spruce, and Paul Woodford. 2015. Preface: Why social justice and music education? In The Oxford handbook of social justice in music education, edited by Cathy Benedict, Patrick Schmidt, Gary Spruce, and Paul Woodford, 204-20. New York, NY: Oxford University Press.

Bennett, H. Stith 1983. Notation and identity in contemporary popular music. Popular Music 3: 215-34.

Bennett, Joe. 2015. Creativities in popular songwriting curricula: Teaching or learning? In Activating diverse musical creativities: Teaching and learning in higher music education, edited by Pamela Burnard, and Elizabeth Haddon, 37-56. London: Bloomsbury.

Björnberg, Alf. 1993. Teach you to rock? Popular music in the University Music Department. Popular Music 12 (1): 69-77.

Bouij, Christer. 2004. Two theoretical perspectives on the socialization of music teachers. Action, Criticism, and Theory for Music Education 3 (3): 1-14.

Bowman, Wayne. 2007. Who is the "we"? Rethinking professionalism in music education. Action, Criticism, and Theory for Music Education 6 (4): 109-31.

Kivijärvi, Sanna, and Lauri Väkevä. 2020. Considering equity in applying Western standard music notation from a social justice standpoint: Against the notation argument. Action, Criticism, and Theory for Music Education 19 (1): 153-73. https://doi.org/10.22176/act19.1.153 
Bradley, Deborah. 2015. Hidden in plain sight. Race and racism in music education. In The Oxford handbook of social justice in music education, edited by Cathy Benedict, Patrick Schmidt, Gary Spruce and Paul Woodford, 220-33. New York, NY: Oxford University Press.

Corrigall, Kathleen A., and Laurel J. Trainor. 2011. Associations between length of music training and reading skills in children. Music Perception 29 (2): 14755 .

Darrow, Alice-Ann. 2008. Music and literacy. General Music Today 21 (2): 3243.

Dunbar-Hall, Peter, and Kathryn Wemyss. 200o. The effects of the study of popular music on music education. International Journal of Music Education 36 (1): $23-34$.

Elliott, David J. 1995. Music matters: A new philosophy of music education. New York: Oxford University Press.

Elliott, David J. 2009. Praxial music education: Reflections and dialogues. New York: Oxford University Press.

Elliott, David J., and Marissa Silverman. 2015. Music matters: A philosophy of music education. New York: Oxford University Press.

Fautley, Martin. 2017. Editorial: Notation and music education. British Journal of Music Education 34 (2): 123-26.

Flaugnacco, Elena, Luisa Lopez, Chiara Terribili, Marcella Montico, Stefania Zoia, and Daniele Schön. 2015. Music training increases phonological awareness and reading skills in developmental dyslexia: A randomized control trial. PloS One 10 (9). https://journals.plos.org/plosone/article?id=10.1371/journal. pone.0138715

Gaare, Mark. 1997. Alternatives to traditional notation. Music Educators Journal 83 (5): $17-23$.

Garfias, Robert. 1993. The Okinawan Kunkunshi notation system and its role in the dissemination of the Shuri court music tradition. Asian Music 25 (1/2): $115-44$.

Gudmundsdottir, Helga Rut. 2010. Advances in music-reading research. Music Education Research 12 (4): 331-38.

Kivijärvi, Sanna, and Lauri Väkevä. 2020. Considering equity in applying Western standard music notation from a social justice standpoint: Against the notation argument. Action, Criticism, and Theory for Music Education 19 (1): 153-73. https://doi.org/10.22176/act19.1.153 
Green, Lucy. 2002. How popular musicians learn: A way ahead for music education. Aldershot: Ashgate.

Hasu, Johanna. 2017. Kun siihen pystyy kuitenkin, ei oo mitään järkee olla tekemättä. Oppimisen vaikeudet pianonsoiton opiskelussa - oppilaiden kokemuksia ja opetuksen keinoja ["Since it can be done, there's no reason not to do it." Learning difficulties in studying the piano students' experiences and teaching methods]. Doctoral dissertation. University of Jyväskylä, Finland.

Hargreaves, David J., Ross Purves, Graham Welch, and Nigel Marshall. 2007. Developing identities and attitudes in musicians and classroom music teachers. British Journal of Educational Psychology 77 (3): 665-82.

Hess, Juliet. 2013. Radical musicking: Challenging dominant paradigms in elementary music education. Doctoral dissertation. University of Toronto.

Hess, Juliet. 2017. Equity in music education: Why equity and social justice in music education? Music Educators Journal 104 (1): 71-3.

Hultberg, Cecilia. 2002. Approaches to music notation: The printed score as a mediator of meaning in Western tonal tradition. Music Education Research 4 (2): $185-97$.

Hwang, Jun-yon, Jin-Ah Kim, and Yong-Sik Yi. 2010. Musical notations of Korea. Seoul, Korea: National Gugak Center.

Junda, Mary Ellen. 1994. Developing readiness for music reading: Developing readiness skills for music reading is a necessity. Music Educators Journal 81 (2): 31-47.

Johnson, Bob. 2004. A sound education for all: Multicultural issues in music education. Educational Policy 18 (1): 116-41.

Karlsen, Sidsel, and Heidi Westerlund. 2015. Music teachers' repertoire choices and the quest for solidarity: Opening arenas for the art of living with difference. In The Oxford handbook of social justice in music education, edited by Cathy Benedict, Patrick Schmidt, Gary Spruce and Paul Woodford, 373-87. New York, NY: Oxford University Press.

Kelly-McHale, Jacqueline, and Carlos Abril. 2015. The space between worlds: Music education and Latino students. In The Oxford handbook of social justice in music education, edited by Cathy Benedict, Patrick Schmidt, Gary Spruce and Paul Woodford, 186-202. New York, NY: Oxford University Press.

Kivijärvi, Sanna, and Lauri Väkevä. 2020. Considering equity in applying Western standard music notation from a social justice standpoint: Against the notation argument. Action, Criticism, and Theory for Music Education 19 (1): 153-73. https://doi.org/10.22176/act19.1.153 
Kivijärvi, Sanna. 2019. Applicability of an applied music notation system: A case study of Figurenotes. International Journal of Music Education 37 (4): 65466. https://doi.org/10.1177/0255761419845475

Kopiez, Reinhard, and Ji In Lee. 2006. Towards a dynamic model of skills involved in sight-reading music. Music Education Research 8 (1): 97-120.

Kopiez, Reinhard, and Ji In Lee. 2008. Towards a general model of skills involved in sight-reading music. Music Education Research 10 (1): 41-62.

Kuo, Yi-Ting, and Ming-Chuen Chuang. 2013. A proposal of a color music notation system on a single melody for music beginners. International Journal of $\mathrm{Mu}$ sic Education 31 (4): 394-412.

Kwami, Robert Mawuena. 2001. Music education in and for a pluralist society. In Issues in Music Teaching, edited by Chris Philpott, and Charles Plummeridge, 142-55. London: Routledge.

Laes, Tuulikki, and Heidi Westerlund. 2018. Performing disability in music teacher education: Moving beyond inclusion through expanded professionalism. International Journal of Music Education 36 (1): 34-46.

Lane, Jeremy. 2006. Undergraduate instrumental music education majors' approaches to score study in various musical contexts. Journal of Research in Music Education 54 (3): 215-30.

Lilliestam, Lars. 1996. On playing by ear. Popular Music 15 (2): 195-216.

López-Íñiguez, Guadalupe, and Juan Ignacio Pozo. 2014. The influence of teachers' conceptions on their students' learning: Children's understanding of sheet music. British Journal of Educational Psychology 84 (2): 311-28. https://doi.org/10.1111/bjep.12026

Marin, Cristina, Ma Puy Pérez-Echeverría, and Susan Hallam. 2012. Using the musical score to perform: A study with Spanish flute students. British Journal of Music Education 29: 193-212.

McCarthy, Marie. 2009. Rethinking "music" in the context of education. In Music education for changing times: Guiding visions for practice, edited by Thomas A. Regelski and Terry Gates, 29-37. New York: Springer.

McPherson, Gary. 2005. From child to musician: Skill development during the beginning stages of learning an instrument. Psychology of Music 33 (1): 5-35.

Kivijärvi, Sanna, and Lauri Väkevä. 2020. Considering equity in applying Western standard music notation from a social justice standpoint: Against the notation argument. Action, Criticism, and Theory for Music Education 19 (1): 153-73. https://doi.org/10.22176/act19.1.153 
Merriam, Alan. 1964. The anthropology of music. Evanston, IL: Northwestern University Press.

Meyer, Leonard. 1989. Style and music: Theory, history, and ideology. Philadelphia: University of Pennsylvania Press.

Mills, Janet, and Gary McPherson. 2006. Musical literacy. In The child as musician: A handbook of musical development, edited by Gary McPherson, 15572. New York, NY: Oxford University Press. E-book.

Nettl, Bruno. 1983. The study of ethnomusicology. Urbana and Chicago, Ill.: The University of Illinois Press.

Nolet, Marlene. 2007. Toward a new understanding: Music literacy and orality in music education. Canadian Music Educator 48 (3): 33-7.

Powell, Bryan, Andrew Krikun, and Joseph Michael Pignato. 2015. Something's happening here!: Popular music education in the United States. IASPM Journal 5 (2): 4-22.

Regelski, Thomas A. 1998. Critical theory and praxis: Professionalizing music education. http://www.maydaygroup.org/1998/o4/critical-theory-and-praxisprofessionalizing-music-education/

Regelski, Thomas. A. 2002. On "methodolatry" and music teaching as critical and reflective praxis. Philosophy of Music Education Review 10 (2): 102-24.

Regelski, Thomas A. 2007. Amateuring in music and its rivals. Action, Criticism, and Theory for Music Education 6 (3): 22-50.

Roberts, J. Christopher, and Patricia S. Campbell. 2015. Multiculturalism and social justice: Complementary movements for education in and through music. In The Oxford handbook of social justice in music education, edited by Cathy Benedict, Patrick Schmidt, Gary Spruce, and Paul Woodford, 272-86. New York, NY: Oxford University Press.

Schippers, Huib. 1996. Teaching world music in the Netherlands: Towards a model for cultural diversity in music education. International Journal of Music Education 27 (1): 16-23.

Seeger, Charles. 1958. Prescriptive and descriptive music-writing. The Musical Quarterly 44 (2): 184-95.

Kivijärvi, Sanna, and Lauri Väkevä. 2020. Considering equity in applying Western standard music notation from a social justice standpoint: Against the notation argument. Action, Criticism, and Theory for Music Education 19 (1): 153-73. https://doi.org/10.22176/act19.1.153 
Spruce, Gary. 1999. Music, music education and the bourgeois aesthetic: Developing a music curriculum for the new millennium. In Learning and knowledge, edited by Robert McCormick and Carrie Paechter, 71-86. London: Sage.

Spruce, Gary. 2001. Music assessment and the hegemony of musical heritage. In Issues in Music Teaching, edited by Chris Philpott and Charles Plummeridge, 118-30. London: Routledge.

Swanwick, Keith. 2001. Musical development theories revisited. Music Education Research 3 (2): 227-42.

Tan, Siu-Lan, Elizabeth Wakefield, and Paul Jeffries. 2008. Musically untrained college students' interpretations of musical notation: Sound, silence, loudness, duration, and temporal order. Psychology of Music 37 (1): 5-24.

Tokita, Alison, and David Hughes. 2008. Context and change in Japanese music. In The Ashgate Research Companion to Japanese Music, edited by Alison Tokita, and David Hughes, 1-33. Aldershot, England: Ashgate Publishing Limited.

van Manen, Max. 1991. The tact of teaching: The meaning of pedagogical thoughtfulness. London, Ont.: Althouse Press.

van Manen, Max. 2015. Pedagogical tact. Walnut Creek, Cal.: Left Coast Press.

Väkevä, Lauri, and Heidi Westerlund. 2007. The "method" of democracy in music education. Action, Criticism, and Theory for Music Education 6 (4): 96-108.

Westerlund, Heidi. 1999. Universalism against contextual thinking in multicultural music education-Western colonialism or pluralism? International Journal of Music Education 33: 94-103.

Westerlund, Heidi. 2002. Bridging experience, action, and culture in music education. Studia Musica 16. Doctoral dissertation. Helsinki: Sibelius Academy.

Yoo, Hyesoo. 2017. Multicultural choral music pedagogy based on the Facets Model. International Journal of Music Education 104 (1): 34-9.

Kivijärvi, Sanna, and Lauri Väkevä. 2020. Considering equity in applying Western standard music notation from a social justice standpoint: Against the notation argument. Action, Criticism, and Theory for Music Education 19 (1): 153-73. https://doi.org/10.22176/act19.1.153 


\section{Notes}

${ }^{1}$ Beyond music education, the ability to read music is associated with being a musician (cf. the term "sheet music" in English language).

2 Some musics are highly context-dependent and not allowed to be written down (e.g., Westerlund 1999, 2002).

3 An exemplary context of wide application of WSMN is the Basic Education in the Arts (BEA) extracurricular music education in Finland. Accomplishing studies within BEA is a prerequisite for applying to many higher education institutions in music, and WSMN is a dominant practice in this system.

Kivijärvi, Sanna, and Lauri Väkevä. 2020. Considering equity in applying Western standard music notation from a social justice standpoint: Against the notation argument. Action, Criticism, and Theory for Music Education 19 (1): 153-73. https://doi.org/10.22176/act19.1.153 